\title{
Problemas complejos y políticas públicas: el caso de la epidemia de obesidad en Mexico
}

\author{
Complex problems and public policies: the case of the obesity \\ epidemic in Mexico
}

\author{
Oscar Mauricio Covarrubias Moreno \\ Universidad Nacional Autónoma de México (México) \\ ORCID: https://orcid.org/0000-0002-1240-725X \\ mauri@unam.mx
}

\section{NOTA BIOGRÁFICA}

Doctor en Ciencias Políticas y Sociales por la Universidad Nacional Autónoma de México. Profesor del Instituto Nacional de la Administración Pública de México. Vicepresidente de la Academia Internacional de Ciencias Político-Administrativas (IAPAS, por sus siglas en ingles). Editor de la Revista Internacional de Estudios sobre Sistemas Educativos (RIESED). Columnista de PA TIMES de la American Society for Public Administration (ASPA). Coordinador en México del Proyecto TOGIVE: Transatlantic Open Government Virtual Education, del Programa ERASMUS+ de la Unión Europea. Miembro del Sistema Nacional de Investigadores del CONACYT.

\section{RESUMEN}

Este artículo propone un esquema analítico para comprender la naturaleza compleja de los problemas y cuestiones de política a partir de los siguientes tres argumentos. Primero, que la complejidad está relacionada con el proceso de construcción social que determina qué cuestiones se asumen como problemas públicos y, la forma en que se definen como tales. Segundo, la complejidad tiene que ver también con las «causas materiales» de los propios problemas que involucran múltiples variables y relaciones. Tercero, la complejidad proviene, asimismo de que los problemas sociales cada vez más, ponen en entredicho, los referentes tradicionales de organización y acción de los gobiernos; a saber, los referentes de carácter funcional, espacial, y temporal los cuales, determinan la forma en que abordan los problemas y conciben sus soluciones. De este tercer argumento, nos ocupamos en el presente artículo, analizando el caso de la obesidad que, en el campo de la salud, es un problema social representativo de dicha complejidad.

\section{PALABRAS CLAVE}

Complejidad; transversalidad; transversalidad; obesidad; epidemia; salud pública.

\begin{abstract}
This article proposes an analytical framework to understand the complex nature of policy issues and problems, based on the following arguments. First, that complexity is related to the process of social construction that determines which issues are assumed as public problems and the way in which they are defined as such. Second, complexity also has to do with the «material causes» of the problems themselves that involve multiple variables and relationships. Third, the complexity also comes from the fact that social problems increasingly call into question the traditional referents of government organization and action; namely, the referents of a functional, spatial, and temporal nature which determine the way in which they
\end{abstract}


approach problems and conceive their solutions. We deal with this third argument in this article, analyzing the case of obesity which, in the field of health, is a social problem representative of this complexity.

\title{
KEYWORDS
}

Complexity; mainstreaming; policy formulation; obesity; epidemic; public health.

\author{
SUMARIO \\ INTRODUCCIÓN. 1. PROBLEMAS SOCIALES COMPLEJOS. 2. DIMENSIONES DE LA COMPLEJIDAD \\ DE LOS PROBLEMAS SOCIALES. 2.1. DIMENSIÓN CAUSAL. 2.2. DIMENSIÓN ESPACIAL. 2.3. DIMEN- \\ SIÓN TEMPORAL. 3. LA EPIDEMIA DE OBESIDAD COMO PROBLEMA COMPLEJO. 3.1. DIMENSIÓN \\ CAUSAL. 3.2. DIMENSIÓN ESPACIAL. 3.3 DIMENSIÓN TEMPORAL. CONCLUSIONES Y RECOMEN- \\ DACIONES. REFERENCIAS BIBLIOGRÁFICAS.
}

\section{INTRODUCCIÓN}

Aunque hay acuerdo en que, el tipo de problemas que afectan el bienestar y porvenir de la sociedad son más complejos porque han escalado en términos de tamaño, duración e intensidad, la elaboración de este artículo de carácter teórico conceptual, parte de la premisa de que es necesario seguir trabajando en la operacionalización de esta noción complejidad, para comprender mejor el desafío que representan para la formulación de las políticas.

Este artículo propone un esquema analítico para comprender la naturaleza compleja de los problemas y cuestiones de política a partir de los siguientes tres argumentos. Primero, que la complejidad está relacionada con el proceso de construcción social que determina qué cuestiones se asumen como problemas públi$\cos \mathrm{y}$, la forma en que se definen como tales. Segundo, la complejidad tiene que ver también con las «causas materiales» de los propios problemas que involucran múltiples variables y relaciones. Tercero, la complejidad proviene, asimismo de que los problemas sociales cada vez más, ponen en entredicho, los referentes tradicionales de organización y acción de los gobiernos; a saber, los referentes de carácter funcional, espacial, y temporal los cuales, determinan la forma en que abordan los problemas y conciben sus soluciones.

En otras palabras, aparte de la «construcción social», existe también una especie de "construcción gubernamental» de los problemas, en muchos sentidos desfasada, que no corresponde a la naturaleza y dinámica de los fenómenos sociales actuales que desbordan de manera creciente las divisiones político administrativas, los compartimentos o áreas de política pública, así como la duración de los ciclos de gobierno. De este tercer argumento, nos ocupamos en el presente artículo, analizando el caso de la obesidad que, en el campo de la salud, es un problema social representativo de dicha complejidad.

En este sentido, nuestra hipótesis es que la literatura que vincula la complejidad de los problemas con los referentes de organización y acción de los gobiernos no está tan bien desarrollada. En la discusión reciente, se habla de la necesidad de concebir un nuevo tipo de políticas para hacer frente a los problemas sociales complejos, pero se echa de menos, el análisis sobre los marcos de actuación gubernamental como fuente de dicha complejidad. Si bien existe un cuerpo sustancial de conocimiento, todavía se necesita una gran cantidad de investigación sobre el reto que suponen las distintas dimensiones los problemas sociales para el diseño de políticas.

Si bien el objetivo a largo plazo de tal esfuerzo analítico debería ser catalogar diferentes tipos de problemas y vincularlos empíricamente con los referentes enunciados, el objetivo aquí es más modesto. Implica el desarrollo de un marco analítico para comprender las dimensiones relevantes de la complejidad de los problemas y ofrecer algunas ideas iniciales sobre cómo abordar dicha complejidad a través del diseño de políticas. Si bien, a lo largo del documento, se conceptualiza y destacan ejemplos de la complejidad problemas públicos, nuestro interés como estudio de caso reside en la epidemia de obesidad.

Así, a partir de la hipótesis planteada, del objetivo de operacionalizar la noción de complejidad de los problemas sociales, así como del carácter teórico del artículo, la metodología consistió en realizar una revisión de la literatura para responder a las preguntas: ¿Qué se entiende por dimensiones causal, espacial y temporal de los problemas sociales? y ¿Qué desafíos que representan estas dimensiones para los marcos de actuación tradicionales de los gobiernos? Lo anterior, con el objeto de conceptualizar las dimensiones 
GAPP. Nueva Época - N. 28, marzo 2022 - ISSN: 1989-8991 - DOI: https://doi.org/10.24965/gapp.i28.10886 - [Págs. 81-98]

Problemas complejos y políticas públicas: el caso de la epidemia de obesidad en Mexico

Oscar Mauricio Covarrubias Moreno

propuestas como parte del marco analítico que se aplica posteriormente al examen de la epidemia de obesidad. Derivado de esta última actividad, se enuncian algunas ideas que responden a la pregunta: ¿Cuáles son los atributos básicos de las políticas para enfrentar los problemas sociales complejos?

Para cumplir con su propósito, el artículo se ha estructurado en cuatro apartados, a saber: 1. Problemas sociales complejos; 2. Dimensiones de la complejidad de los problemas sociales; 3. La epidemia de obesidad como problema complejo; y Conclusiones y recomendaciones.

\section{PROBLEMAS SOCIALES COMPLEJOS}

Los problemas sociales generalmente están asociados con la idea de que «se debe hacer algo», representan condiciones que no deberían permitirse que continúen, que requieren que la sociedad reaccione ante ellos y encuentre soluciones. Mientras que los problemas privados son asuntos que deben resolver las personas involucradas, los problemas sociales exigen una respuesta pública. Al iniciar la tercera década del siglo XXI, una lista de problemas sociales podría incluir la desigualdad, inseguridad, desempleo, pobreza, corrupción, impunidad, narcotráfico, escasez de agua, falta de vivienda, discriminación, cambio climático y la obesidad, objeto de nuestro interés. Lo que tienen en común, es que son cuestiones que han captado la atención y preocupación de la sociedad en el momento actual.

No obstante, lo que atrae la atención pública en cada lugar es probable que difiera, al menos en algunos aspectos, de lo que se considera un problema social en otro sitio o contexto. También es cierto que, si se mira hacia atrás, sólo una parte de la lista de problemas de ahora tendrían visibilidad; hay dos posibles explicaciones para tales diferencias. Una, es que los problemas sociales cambian. La otra, que lo que se percibe como un problema social también puede cambiar.

Al hacer la distinción entre "problemas personales» y «problemas públicos», el sociólogo estadounidense Wright Mills (1959) sugirió que, un factor que puede hacer una diferencia en si las cosas se perciben como problemas privados o públicos, es la escala o volumen de la población y lugares afectados. Si sólo unas pocas personas experimentan algún tipo de problema, es probable que siga siendo un asunto privado y no atraiga la preocupación pública. Pero, si un gran número de personas comienzan a experimentar este mismo problema, o temen que puedan hacerlo, puede llegar a convertirse en un problema público. En este punto, es importante tener en cuenta que los problemas individuales a menudo surgen o son provocados por la sociedad misma (Barkan, 2014). Mills consideró que muchos problemas que normalmente se consideran privados se entienden mejor como problemas públicos, acuñando el término «imaginación sociológica» para referirse a la capacidad de apreciar la base estructural de los problemas individuales.

Como parte del proceso de conceptualización/operacionalización, del carácter complejo de los problemas sociales, nos apoyaremos en Morcol (2012) quien formula las siguientes interrogantes acerca de la complejidad: ¿Se encuentra en la naturaleza de las cosas? ¿O es una función de la forma en que los seres humanos conocen las cosas en sus mundos? En otras palabras, ¿es ontológica o epistemológica o ambas? Así, ¿Un asunto es complejo porque quizás está más allá de la comprensión de nuestras capacidades cognitivas? o bien, porque ¿existe un desajuste entre la forma en que funcionan nuestras mentes y la forma en que son las cosas?

De acuerdo con lo anterior, podemos distinguir de entrada que, el carácter complejo de los problemas sociales está relacionado con dos razones. La primera, con un proceso de construcción social que determina qué cuestiones se definen como problemas sociales. Lo cual, apunta a que debe existir la percepción de que una condición o comportamiento debe ser abordado para que sea considerado un problema social (Rubington y Weinberg, 2010). La segunda, se refiere a la «causas materiales» de los problemas; al hecho de que involucran relaciones inciertas entre las variables a nivel causal (Mballa, 2015). Circunstancias donde un pequeño cambio en una variable puede producir cambios mucho mayores en otras variables o condiciones como en el caso clásico de la teoría del caos, acerca del aleteo de una mariposa que potencialmente puede causar un huracán.

Por nuestra parte, planteamos que hay una tercera razón de la complejidad los problemas sociales la cual, tiene que ver con el hecho de que ponen en entredicho, cada vez más, los referentes o frameworks tradicionales de organización y acción de los gobiernos; los referentes de carácter funcional, espacial, y temporal que determinan la forma en que abordan los problemas y conciben sus soluciones. En otras palabras, además de la «construcción social», existe también una especie de «construcción gubernamental» de los problemas, en muchos sentidos pasada de moda, que no corresponde a la naturaleza y dinámica de 
los fenómenos sociales actuales que desbordan crecientemente las divisiones político administrativas, los compartimentos o áreas de política pública, así como la duración de los ciclos electorales y de gobierno. De esta tercera razón, nos ocuparemos en el segundo apartado.

Con respecto a la primera de las razones, Lenoir (1986) y Roth (2002) distinguen tres fases en la construcción social de los problemas. Inicialmente, se necesita que haya una transformación en la vida cotidiana de los individuos originada por cambios que afectan de manera diferenciada a los grupos sociales lo cual, genera una tensión que las personas perciben una situación, explícita o implícitamente como problemática. La segunda fase, tiene que ver con la transformación de un problema de carácter privado, en un problema social (colectivo), y consecuentemente, encontrar una formulación pública. Esto, implica que las personas o grupos promotores tengan la capacidad de darle visibilidad al problema, lo definan y lo comuniquen en un lenguaje propicio para los medios de expresión pública. Finalmente, la tercera fase consiste en la institucionalización del problema. Es decir, que una vez reconocido como social y formulado como tal, se produzca una intervención pública.

En los sistemas políticos democráticos contemporáneos, las agendas políticas se centran retóricamente en los problemas que los líderes y las partes interesadas creen que merecen atención y debate (Peters, 2005). Un aspecto central de lo que es «social» acerca de los problemas, es la forma en que estos problemas se perciben, definen y comprenden socialmente (Thissen, 2013). Diferentes problemas privados se definen como sociales en sociedades particulares y en períodos específicos a través de un complejo proceso de definición/redefinición.

En este orden de ideas, el proceso de políticas públicas es complejo, debido a la gran cantidad de formas en que los seres humanos interpretan las realidades a su alrededor lo que da lugar a desacuerdos entre los interesados. Los problemas sociales complejos, retomando a Head (2019), dan lugar a puntos de vista divergentes sobre la naturaleza de los problemas, su importancia relativa y las respuestas apropiadas. Los desacuerdos surgen porque los puntos de vista de las partes interesadas clave, se encuentran anclados en diferentes supuestos, valores, intereses y capacidades. Estas diferencias de perspectiva tienen consecuencias importantes, ya que la forma en que se define un problema, estará relacionada con las acciones correctivas preferidas para abordarlo.

La segunda razón de la complejidad de los problemas sociales, reside en que, además de involucrar a múltiples actores, intereses, y puntos de veto, involucran relaciones inciertas entre las variables a nivel causal (Peters, 2005). Las sociedades operan en entornos dinámicos en los que predominan los problemas que devienen más difíciles (Bendor, 2015). Actualmente, las organizaciones públicas, privadas y sociales alrededor del mundo deben operar y enfrentar desafíos sin precedentes en un entorno global cada vez más volátil, incierto, complejo y ambiguo (elementos del acrónimo en inglés VUCA). La crisis del COVID-19 es un ejemplo dramático de nuestros contextos gravemente perturbados (UGM Consulting, 2020; Covarrubias, 2020).

Así, retomando las interrogantes de Morcol, aunque en la complejidad de los problemas sociales está relacionada con el proceso de construcción social, sin lugar a dudas, reside también en la naturaleza misma de los problemas. Los teóricos de la complejidad no ofrecen una definición unívoca, pero hay consenso en que la complejidad de los fenómenos o sistemas, sean sociales o naturales, es producto de relaciones no lineales en tanto propiedad emergente (Rescher, 1998; Mitchell, 2009).

Por ejemplo, el calentamiento global es complejo, no sólo porque hay muchas interpretaciones sobre él, las cuales están relacionadas con las percepciones individuales y grupales de sus propios intereses y el sistema de valores dominante en las sociedades. También es complejo, porque los procesos naturales que genera el calentamiento global (condiciones atmosféricas, interacciones entre los niveles de gases de efecto invernadero en la atmósfera con las temperaturas, etc.) son complejos (Morcol, 2012). Por lo tanto, una buena comprensión de las complejidades naturales de los problemas debería ser parte de la comprensión de las complejidades de las políticas.

Asimismo, dado que muchos problemas no se han resuelto o mitigado, al agravarse se han hecho crónicos escalando en complejidad, permaneciendo así, en la agenda de las preocupaciones sociales. Cuando hablamos de que se han vuelto crónicos y más complejos, es porque afectan a una mayor población en más lugares, pero también, porque lo hacen de una manera más profunda y duradera. En otras palabras, este tipo de problemas: «no nacen de un día para otro», involucran un mayor número de factores causales, y están relacionados con procesos de largo plazo, tanto en su gestación como en sus consecuencias. Sobre esto último, como veremos más adelante, la epidemia de obesidad es un caso representativo de problemas 
con un patrón de deterioro lento que se extiende más allá del plazo en que los gobiernos elaboran sus planes y presupuestos (Olson, 2016).

Podemos cerrar este primer apartado, señalando que, si bien es cierto que la definición de un problema es un problema político que mucho tiene que ver con el proceso de construcción social, no significa que se deba desatender la necesidad avanzar en una definición más objetiva de los mismos. De acuerdo con Roth (2002), esta tarea debería ser seriamente asumida por la administración pública, las universidades y centros de investigación, con el objetivo de proporcionar una información que permita conocer mejor el problema antes de que se tome una decisión. La capacidad de conocer las dimensiones de un problema, permitiría llevar a cabo una discusión más argumentada con los actores políticos que reclaman una intervención y, así legitimar más la acción del Estado. En este sentido, la definición del problema consistirá entre otras cosas, en determinar la naturaleza, las causas, el alcance, la temporalidad, la dinámica o evolución, los afectados directos e indirectos, así como sus consecuencias presentes y futuras.

\section{DIMENSIONES DE LA COMPLEJIDAD DE LOS PROBLEMAS SOCIALES}

De acuerdo con lo que planteamos en la sección anterior, aparte del proceso de construcción social y de su propia naturaleza, la complejidad de los problemas sociales radica también, en su cuestionamiento a los referentes o policy frameworks que guían la forma en que los gobiernos los abordan y conciben sus soluciones. Nos referimos específicamente al referente funcional, que apunta a los sectores, compartimentos o áreas de política existentes; al referente espacial, que alude a las divisiones político administrativas o jurisdicciones territoriales; así como, al referente temporal, relacionado con la duración de los ciclos o periodos de gobierno.

Aunque hay acuerdo en que, el tipo de problemas que afectan a la sociedad son más complejos porque han escalado en términos de tamaño, duración e intensidad, afectando con ello, a más personas y lugares de manera más profunda, consideramos necesario "operacionalizar» esta complejidad para poder comprender mejor el desafío que representan para la formulación de las políticas (Covarrubias, 2018).

Un modo en que podemos aproximarnos a este desafío, es caracterizando a los problemas sociales como «cuestiones transversales», cuya naturaleza y dinámica ponen en entredicho y desestabilizan los referentes que tradicionalmente estructuran la organización y acción de los gobiernos; en otras palabras, que no respetan las divisiones sectoriales (funcionales), los límites territoriales (espaciales) y los horizontes temporales (ciclos de gobierno).

Estos referentes o policy frameworks, configuran la organización y el ejercicio del poder de los sistemas políticos y administrativos, enmarcando la forma en que se definen los problemas sociales y sus soluciones (Peters, 2005; Bacchi, 2009). La actividad de «enmarcado», es crucial para la forma en que se representan los debates sobre problemas, contextos y respuestas. Se trata de una forma de seleccionar, organizar, interpretar y dar sentido a una realidad compleja que proporciona guías para conocer, analizar, persuadir y actuar (Rein y Schön, 1996). De este modo, los problemas elegidos para la atención de las políticas y la manera en que se formulan, generalmente reflejarán la estructura y organización de los gobiernos en términos funcionales, espaciales y temporales.

Así, mientras del lado de los gobiernos, se tienen referentes o policy frameworks que determinan los marcos de actuación, por el lado de los problemas sociales, tenemos dimensiones, escalas y dinámicas que desbordan de manera creciente las soluciones ancladas en estos referentes. A saber:

Dimensión. Para nuestro propósito, retomamos los significados de: Importancia o relevancia de algo, por ejemplo, un fenómeno de grandes dimensiones; Aspecto o faceta de algo; Coordenada, en tanto que guía y determina una posición de algo en el espacio o tiempo; Parámetro o variable, asignada a una propiedad o atributo; y Extensión, como magnitud, tamaño o alcance, que denota el rango o el grado en que algo se extiende, por ejemplo, las dimensiones sociales y políticas de un problema [RAE (https://dle.rae.es), Merriam (https://www.merriam-webster.com)].

Escala. Inherente al concepto de dimensión, como sustantivo alude a proporción, extensión o magnitud en que se desarrolla algo, en nuestro caso, un problema o fenómeno social. Así, cuando hablamos de "gran escala», significa que involucra a muchas personas y cubre o abarca un área extensa (Merriam, 2020). Como verbo, escalar consiste en ascender según las proporciones de una de medición establecida. En términos de causalidad, esto representa una mayor complejidad por el número de factores y variables 
involucrados. Un problema puede ser considerado un síntoma de otro (Head, 2019), pero también, al interactuar con otros, puede ser parte de un sistema de problemas interrelacionados (Ackoff, 1974). Así, la descripción de un fenómeno puede realizarse a diferentes dimensiones o escalas: espacial, funcional y temporal (Gershenson, 2006; Morin, 2006).

Dinámica. Se trata de una propiedad clave para determinar la naturaleza y los efectos de un fenómeno. Los problemas complejos, en tanto suma de factores que caracterizan un determinado estado de cosas o una situación, tienden a cambiar sus estados a menudo, mostrando comportamientos impredecibles a largo plazo. En la dimensión temporal, los fenómenos sociales pueden analizarse en términos de los cambios de sus estados a lo largo del tiempo. Lo cual, nos conecta a su vez, con la dimensión funcional o causal, ya que a medida que el fenómeno cambia su estado de uno a otro, sus causas o variables involucradas también cambian (Ramis, 2004). Los problemas sociales suelen ser no lineales y cambian a diferentes velocidades según sus estados y el entorno; en este sentido, su trayectoria y estado futuro dependen no sólo de su estado actual, sino también de su historia pasada (Domenico y Sayama, 2019).

Como parte de nuestro proceso de operacionalización de la complejidad de los problemas sociales en términos de la formulación de políticas, a continuación, delineamos las dimensiones espacial, causal y temporal que dan cuenta, por un lado, de la naturaleza y comportamiento de dichos problemas. Por otro, de las dificultades que dichos problemas representan para los referentes o policy frameworks tradicionales.

\subsection{Dimensión causal}

Esta primera dimensión del carácter complejo de los problemas sociales, destaca las numerosas causas y variables que involucran, lo que hace que su atención interese o atraviese a los distintos sectores o áreas de política pública en las que tradicionalmente se encuentran organizados los gobiernos. La mayoría de las grandes cuestiones sociales de nuestro tiempo, se han hecho transversales; debido a que su atención no depende de un solo ministerio, departamento, sino que "caen» en una zona de jurisdicciones mezcladas (Prats, 2005; Covarrubias, 2018).

La naturaleza multicausal o multifactorial de los problemas no puede estar mejor ilustrada que con la pobreza. La creciente convergencia de desventajas, expresada en indicadores sociales estrechamente conectados entre sí, cada vez más, pone en entredicho las estructuras y compartimentos convencionales existentes en las administraciones públicas.

A lo anterior, hay que añadir que los problemas se encuentran entrelazados mediante innumerables circuitos, interactúan entre sí, muy a menudo y en formas impredecibles. El nivel de interconexión existente hace que los cambios en cualquier lugar repercutan inesperadamente y, a veces, peligrosamente en todo el sistema (Luke, 1998; Bryson et al., 2006). En un entorno globalizado, las causas de los fenómenos sociales se encuentran relacionadas a movimientos que escapan al control de los gobiernos, incrementando la interdependencia y la vulnerabilidad. Para Johnson (2006), tenemos problemas que no pueden ser resueltos por métodos convencionales; esto se debe a que están mucho más conectados de lo que eran antes y, a que dicha conectividad, permite que las cosas se propaguen rápidamente.

Innerarity y Solana (2011) hablan del "carácter epidémico» de la sociedad contemporánea: contaminación, contagio, inestabilidad, encadenamientos, turbulencias, fragilidad compartida, afectación universa y superexposición. Todos estos fenómenos que, forman parte del lado oscuro del mundo globalizado y aumentan la vulnerabilidad. Walker et al. (2013) apuntan que, debido a la globalización, los problemas y las interrelaciones entre los sistemas, las consecuencias de tomar decisiones políticas incorrectas se han vuelto más serias y globales, incluso potencialmente catastróficas.

Una muestra clara, es la crisis provocada por un minúsculo agente, de unos 0,000125 milímetros, localizado quizás en un mercado de Wuhan, una populosa ciudad en la provincia de Hubei, en China. El virus SARS-Cov-2, causante de la enfermedad COVID-19, ha puesto en jaque a líderes del planeta y gobiernos. Y deja a poblaciones enteras en zonas acomodadas de países desarrollados, en un estado de semiexcepción (Bassets, 2020). En menos de tres meses, este microscópico agente patógeno, ralentizó el comercio, los viajes y la industria colocando a la economía global en el momento más crítico desde la crisis financiera que se apoderó del mundo en 2008-2009.

Como veremos más adelante, en el ámbito de la salud, la interacción de las enfermedades contagiosas, resulta en patrones muy complejos de propagación a través de una población al mismo tiempo, por lo que 
tener esto en cuenta, podría conducir a un mejor seguimiento e intervención cuando múltiples enfermedades interactúan y se refuerzan unas a otras (University of Vermont, 2020). Bajo las dinámicas llamadas «simples», generalmente se acepta que el tamaño previsto de la epidemia será proporcional a la tasa de transmisión. Sin embargo, la presencia de un contagio más en la población puede cambiar drásticamente la dinámica de lo simple a lo complejo (Hébert-Dufresne et al., 2020). Una vez que ocurre este cambio, los cambios microscópicos en la tasa de transmisión desencadenan saltos macroscópicos en el tamaño epidémico esperado.

Frente a las múltiples causas, factores y determinantes de los problemas sociales, cada vez es más necesaria y la colaboración interministerial e intergubernamental. Pero también, entre los gobiernos nacionales, las organizaciones de la sociedad civil, el sector privado y otros miembros y organizaciones de la comunidad mundial (Bryson et al., 2006). Es difícil imaginar abordar con éxito los grandes problemas sociales, sin este tipo de entendimiento y coordinación.

\subsection{Dimensión espacial}

La segunda dimensión se refiere, por un lado, a que los problemas sociales complejos se desplazan en diferentes escalas: local, regional, nacional y global. Por otro, a que al ignorar las fronteras político-administrativas existentes, los problemas desarrollan su propia geografía; más aún, a que los mapas de los distintos fenómenos se superponen creando un complejo diseño cartográfico que perturba a las administraciones públicas, tan acostumbradas a maniobrar de acuerdo con una visión territorializada.

Entre sus orígenes y sus efectos, pueden mediar grandes distancias, como lo ejemplifica el fenómeno de la inmigración o del narcotráfico en el que productores, grandes distribuidores y consumidores frecuentemente se encuentran en regiones distintas. Son también de asuntos que, en esta fase de desarrollo mundial, adquieren una dimensión que rebasa los ámbitos nacionales y requieren ser abordados por los gobiernos de diferentes países en forma bilateral o multilateral; a nivel regional, continental, e incluso global.

Como apunta (Courtney, 2001), la globalización suele ser la razón detrás de la creciente complejidad de los problemas. Caracterizada por la dispersión de la producción y la movilidad de los flujos de capital e información, la globalización conlleva de manera simultánea la propagación de otros importantes fenómenos sociales que, al igual que las actividades económicas, se despliegan en el ámbito «supra» o global y no en los confines territoriales y jurídicos del Estado-nación. En palabras de Sassen (2003), el fortalecimiento y formación de las cuestiones globales, se asienta sobre la existencia de un sistema económico global y en el desarrollo paralelo de diferentes soportes institucionales para los flujos monetarios y mercados transfronterizos.

Resultado del profundo efecto que las tecnologías de la información y la comunicación hablar de la geografía de las cuestiones globales, implica aludir a una espacialidad no solo real, sino también virtual. Para Allen (2017), el avance de la tecnología, la intersección del entorno construido y el natural, así como la interacción global de culturas, personas y estados nacionales son tres fuerzas que, al alejarnos de las fronteras descritas geográfica y físicamente, nos acercan a las fronteras virtuales; fronteras con elementos que no respetan las fronteras tradicionales y que convergen para crear complejidad a una escala que nunca antes vista.

A manera de ejemplo, conviene mencionar que los impactos del transporte aéreo y los cambios en el control la gobernanza de las enfermedades infecciosas, se encuentran relacionados con el impresionante aumento en el número de pasajeros aéreos, así como con la frecuencia y extensión geográfica de los vuelos de larga distancia, que han planteado nuevos desafíos para el control internacional de enfermedades y la prevención sanitaria. De acuerdo con datos de la Asociación Internacional de Transporte Aéreo (IATA, 2018), en 2019 más de 4.500 millones de pasajeros abordaron vuelos comerciales en el mundo y se estima que el número aumentará a 8.200 millones para 2037.

En suma, la dinámica de los fenómenos sociales contrasta o pone en cuestionamiento la estabilidad de las fronteras definidas de acuerdo a criterios políticos, funcionales, territoriales, temporales o incluso culturales. Los mapas creados por los problemas públicos no tienen fronteras fijas; por el contrario, éstas se definen o modifican al ritmo de su propia dinámica y virulencia. Se trata de fenómenos que no conocen límites, ni se detienen ante ninguna barrera, cuyas causas se encuentran interrelacionadas o mutuamente determinadas. Por esta razón, los mapas político político-administrativos ya no son muy útiles para comprenderlos y menos aún para contenerlos. 


\subsection{Dimensión temporal}

La tercera dimensión se refiere a que los problemas sociales complejos, conllevan causas, procesos, consecuencias y soluciones de larga duración. La mayoría de ellos, son la expresión de una serie de factores económicos, sociales, políticos y culturales combinados, acumulados históricamente, no resueltos y agravados por la aparición de otros nuevos. Se trata de cuestiones de naturaleza no coyuntural que, por tanto, demandan políticas públicas de largo aliento que trasciendan los periodos electorales y de gobierno.

El deterioro del medio ambiente y la reversión de sus daños; el cambio demográfico que trae consigo el envejecimiento de la población; el agotamiento de los acuíferos; el creciente daño a los ecosistemas; la pérdida gradual de la biodiversidad; así como la epidemia de obesidad objeto de nuestro interés, por citar algunos, son problemas que tienen una cronología distinta a los ciclos de vida de los gobiernos (Walker et al., 2013; Covarrubias, 2018), Y que, en términos de política pública, demandan respuestas de fondo y largo aliento que actúen sobre los factores estructurales, más que sobre sus manifestaciones coyunturales.

A la incapacidad o falta de voluntad para percibir las conexiones entre los distintos problemas, debe añadirse el hecho de que la complejidad dificulta la generación de evidencias para mejorar la hechura de las políticas. Las largas demoras de tiempo, sugieren que en realidad nunca experimentamos plenamente las consecuencias de nuestras acciones.

Los retrasos en los procesos de retroalimentación son comunes y particularmente problemáticos al dilatar la acumulación de evidencias, ocasionando mayor ambigüedad en los impactos a corto y largo plazo de nuestras acciones u omisiones: «fumar da placer inmediato, mientras que el cáncer de pulmón se desarrolla durante décadas» (Sterman, 2006). Esta complejidad, dificulta la capacidad de descubrir los efectos retardados o distantes de las intervenciones, dando lugar a efectos colaterales; además de que, abundan los efectos de retroalimentación complejos (Senge 2006). Así, en muchas ocasiones se empeoran los problemas que se pretenden resolver, precisamente por un feedback débil y lento.

Aunado a lo anterior, el llamado «sesgo presentista» impide anticipar los problemas del mañana, proteger el interés público a largo plazo y esforzarse por preparar al Estado para afrontar el futuro (Thaler y Sunstein, 2008; Innerarity, 2009; Kahneman 2020). Entre las cuestiones que pueden ser pasadas por alto o mal abordadas por los gobiernos, se encuentra una clase particular de problemas de política que se conocen como «progresivos», «lentos», o «emergentes». Este tipo de problemas, tienden a crecer gradualmente y, a veces de manera imperceptible, con un largo retraso entre las causas y sus efectos (Olson, 2016). De manera que, los impactos negativos y su potencial para causar un daño significativo a largo plazo, pueden estar en el radar de los «expertos», pero generalmente carecen de señales de alerta temprana que puedan servir para movilizar la preocupación pública y, provocar o dar lugar a una respuesta gubernamental.

Muchos de los problemas y riesgos a los que se enfrentan los gobiernos, están identificados por organizaciones internacionales, grupos de expertos e instituciones que realizan análisis detallados y periódicos (Boston, 2017). Un ejemplo, es el Foro Económico Mundial, que publica un informe anual sobre riesgos globales (World Economic Forum, 2015).

En este contexto, como veremos más adelante, la obesidad no es un shock repentino, sino un problema que ha tardado décadas en desarrollarse, por lo que llevará también muchos años controlarlo; el aumento en su escala y ritmo deben verse como resultado de un proceso de cambio social, económico y tecnológico (Lang y Rayner, 2007). Por lo tanto, parte de la búsqueda de soluciones, debe ser investigar cuáles han sido los impulsores de la obesidad a lo largo del tiempo, y cómo han interactuado.

En síntesis, desde la perspectiva temporal, la complejidad de los problemas sociales, se explica porque trascienden los horizontes de planificación acotados tradicionalmente a la duración de los ciclos de gobierno y que, por la usual falta de continuidad, deja al margen y a la incertidumbre, la atención, evolución y efectos futuros de dichos problemas.

Las tres dimensiones bosquejadas, pueden representarse gráficamente mediante el sistema de coordenadas que se muestra en la Figura 1. En el Eje $Y$, la Dimensión espacial se refiere a la magnitud de la afectación territorial o jurisdiccional causada por los problemas públicos. En el Eje $X$, la Dimensión causal, representa la naturaleza multifactorial de los fenómenos sociales que atraviesan los diferentes compartimentos dominios de política. Por su parte, en el Eje Z, la Dimensión temporal, se refiere a que los problemas públicos complejos, y su resolución, están asociados a procesos cuya temporalidad rebasa la duración de los ciclos o periodos de gobierno. 
Figura 1. Carácter complejo de los problemas sociales en tRes dimensiones

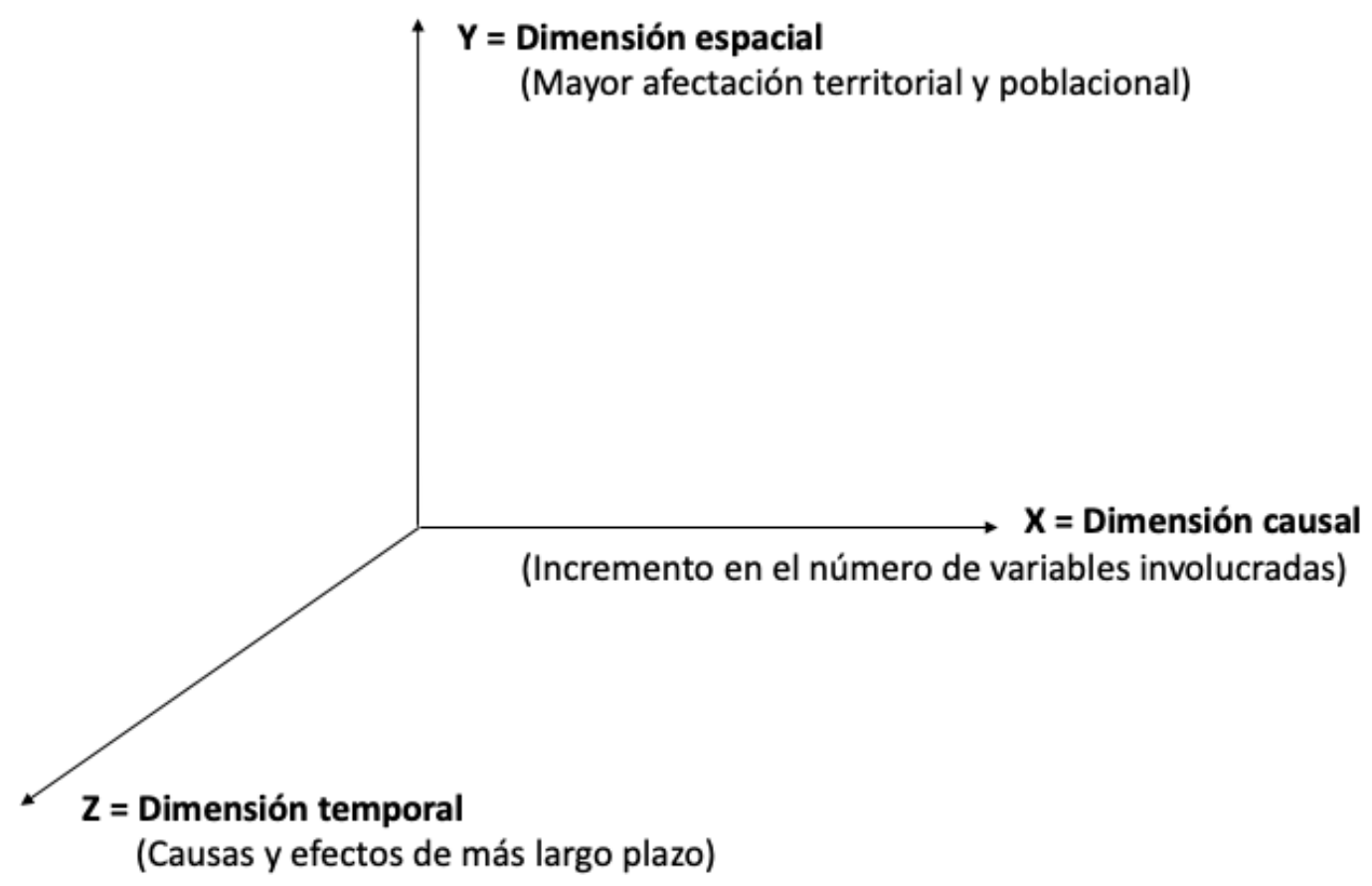

Fuente: Elaboración propia.

De esta manera, la complejidad de los problemas sociales, en términos de la estructura y organización del gobierno, tiene que ver con que son fenómenos transversales en el sentido, de que su escala atraviesa las divisiones y fronteras existentes en cada dimensión, pero también por su desbordamiento a las otras dimensiones (Brugué, 2014). Como la obesidad, objeto de nuestro interés está claro que muchas de los problemas y crisis actuales atraviesan los dominios de política y las fronteras geográficas y temporales (Blondin y Boin, 2020).

Para la OCDE (2014), los gobiernos enfrentan desafíos políticos cada vez más multidimensionales que requieren la implementación de respuestas transversales y multifacéticas. Conviene citar en este punto a Menegoz (2003), quien destaca las consecuencias desestabilizadoras de los efectos transversales de los problemas públicos, ya que ponen bajo estrés al modelo burocrático de organización gubernamental, basado en los principios de división funcional, especialización, linealidad, verticalidad y jerarquía.

Para cerrar este apartado, sobre las dimensiones de la complejidad de los problemas sociales, consideramos conveniente formular algunos apuntes adicionales. El primero, que el amplio rango de problemas sociales que se ubican en esta categoría de cuestiones transversales, continúa extendiéndose abarcando diferentes áreas de política lo cual, puede constatarse a nivel de país, pero también, en agendas regionales y globales.

El segundo apunte que, de manera similar a esta representación tridimensional de la complejidad/transversalidad de los problemas sociales, desde la teoría del riesgo, Beck (1998) plantea, que los fenómenos, tienen lugar en tres niveles: Espacial, en términos de que los nuevos riesgos no respetan naciones, ni estados ni otras fronteras; Temporal, ya que los nuevos riesgos tienen un largo periodo de latencia, de modo que no se puede determinar ni limitar con seguridad su efecto a lo largo del tiempo; y Social, debido a la complejidad de los problemas y a la longitud de las cadenas de efectos, ya no se pueden asignar las causas y consecuencias con algún grado de seguridad.

De manera similar, Brugué (2014) plantea que, en el contexto actual, tanto la política como las políticas públicas se encuentran desbordadas. Una política desbordada genera políticas públicas impotentes. Una impotencia que tiene múltiples orígenes y diversas explicaciones, pero que puede entenderse a través de la superación de las escalas territoriales y temporales (desbordamiento escalar), pero también, de la complejidad como un rasgo estructural de nuestras sociedades (desbordamiento estructural). 


\section{LA EPIDEMIA DE OBESIDAD COMO PROBLEMA COMPLEJO}

Un área de política pública que ilustra las características de los problemas complejos en las dimensiones espacial, causal y temporal, es la salud. La cual, se concibe en el Preámbulo de la Constitución de la Organización Mundial de la Salud (OMS) -adoptada por la Conferencia Sanitaria Internacional de 1946como un estado de completo bienestar físico, mental y social y no meramente la ausencia de enfermedad o dolencia (WHO, 1946).

De acuerdo con la OMS, entre los determinantes de la salud, se encuentran una gama de factores personales, sociales, económicos y ambientales que determinan el estado de salud de los individuos y poblaciones; los cuales, se agrupan en siete grandes categorías: entorno socioeconómico; entorno físico; desarrollo de la primera infancia; prácticas personales de salud; la capacidad individual y habilidades de afrontamiento; la biología y la dotación genética; así como, los servicios sanitarios (WHO, 1998). Esto es relevante para la comprensión de la salud, pero también para la toma de decisiones sobre problemas relacionados con la misma.

En el enfoque de la OMS, pueden identificarse tres elementos básicos. El primero, la salud como un fenómeno social complejo. El segundo, el conjunto de determinantes incluyen el medio ambiente, estilo de vida, biología humana y sistemas de atención médica. La OMS enfatiza los «determinantes sociales» a los que subclasifica como determinantes de contexto, estructurales e inmediatos. El tercer elemento, las relaciones entre la salud y los determinantes, así como la interacción entre estos últimos (Cifuentes, 2012).

En este orden de ideas, muchos problemas de salud surgen de fuerzas económicas y políticas que sólo pueden ser modificadas por acción colectiva (Capra y Luigi, 2014). Por tanto, la responsabilidad individual, ha de ir acompañada de la responsabilidad social, la asistencia sanitaria individual y por políticas sociales como apuntan. En otras palabras, el mantenimiento de la salud será en parte, un asunto individual y, en parte, un asunto colectivo; y la mayor parte del tiempo, ambos en estrecha relación. «Salud social» es el término con el que la Carta de Ottawa para la Promoción de la Salud de la Organización Mundial de la Salud (WHO, 1986), identifica estas políticas y actividades colectivas, dedicadas al mantenimiento y mejora de la salud pública.

En el campo de la salud, la obesidad es un fenómeno social representativo de la complejidad en las tres dimensiones que hemos planteado. Considerada como un gran desafío epidemiológico la obesidad y las enfermedades asociadas han alcanzado proporciones de crisis (Hurt et al., 2010). Se trata de una enfermedad de etiología múltiple que incluye programación fetal, predisposición genética, mecanismos fisiológicos, factores psicológicos, producción y comportamiento de alimentos, patrón de actividad física, contexto ambiental y social. Los factores de riesgo demográficos, conductuales y socioeconómicos, así como el aumento de la edad, el bajo nivel educativo y el empleo, los hábitos alimentarios desequilibrados y la inactividad física, se destacan como correlatos de la obesidad en todo el mundo (Samouda et al., 2018).

El problema ha crecido hasta proporciones epidémicas, con más de 4 millones de personas que mueren cada año (CIFS, 2019). Las tasas de sobrepeso y obesidad continúan aumentando en adultos y niños. De 1975 a 2016, la prevalencia de niños y adolescentes con sobrepeso u obesidad de entre 5 y 19 años, aumentó más de cuatro veces del $4 \%$ al $18 \%$ a nivel mundial (WHO, 2020).

Desde el punto de vista económico, la obesidad obstaculiza la productividad, sobrecarga los sistemas de salud y disminuye la calidad y la duración de la vida, lo mismo que aumenta el gasto en salud (CIFS, 2019). Asimismo, reducirá el producto interno bruto en un 3,3\% en los países de la OCDE e impactará los presupuestos personales a través de gastos adicionales de hasta 360 dólares per cápita por año. Los países de la OCDE ya gastan el $8,4 \%$ de su presupuesto total de salud, en el tratamiento de enfermedades relacionadas con la obesidad (OECD, 2019).

En la Cumbre sobre la Crisis Global de la Obesidad de 2016, se planteó la necesidad de una acción urgente para detener la propagación de la enfermedad y reducir la escala actual del problema (The Economist, 2016). Debido a su complejidad y magnitud, se reconoció también que es necesaria una estrategia de intervención integral y holística implementada a escala local, regional, nacional y global con la participación de diferentes sectores y áreas de política pública como atención médica, farmacéutica, alimentos y bebidas, marketing, agricultura, nutrición, deportes, asuntos religiosos, cultural y por supuesto, educación. Por ello, es poco probable que las políticas públicas sean efectivas, ni siquiera adoptadas, a menos que haya en paralelo una activación de múltiples sectores y se logre sinergismo (Tarlov, 1999).

Dada su incidencia a nivel global, la reducción de la obesidad es uno de los Objetivos de Desarrollo Sostenible (ODS) acordado para alcanzarse en 2030 (ONU, 2020). Miles de muertes prematuras, podrían 
evitarse si la obesidad se estabilizara o se terminara para 2030 (IDF, 2019). Conviene mencionar de paso, que los ODS dieron visibilidad a diversos objetivos en conflicto o en competencia, es decir, que ya no era una opción perseguir el crecimiento económico mientras aumentaba la contaminación, ni seguir comiendo en exceso en una parte del mundo y morir de hambre en otra, ni alimentar a todos mediante la tala de más bosques para dejar espacio para la agricultura y la ganadería (CIFS, 2020).

En las siguientes páginas, caracterizamos a la obesidad como un problema social complejo, a través de las tres dimensiones delineadas en el apartado anterior. En otras palabras, destacamos que se trata de una enfermedad ampliamente extendida (dimensión espacial), de carácter multifactorial (dimensión causal) y crónica o de larga data (dimensión temporal). Junto con ello, enunciamos algunos de los principales retos que plantean para la formulación de políticas.

\subsection{Dimensión causal}

Como problema de salud pública, la obesidad, representa un fenómeno social complejo en cuya naturaleza convergen múltiples causas y factores de riesgo, que han contribuido a su rápido crecimiento en las últimas décadas, hasta el punto de que, hoy en día, es común hablar de una epidemia o de crisis de obesidad de proporciones globales.

En principio, la obesidad puede caracterizarse como la acumulación excesiva de grasa causada por un desequilibrio energético entre las calorías consumidas y las calorías gastadas. La obesidad se define como una acumulación anormal o excesiva de grasa que presenta un riesgo para la salud. Un índice de masa corporal (IMC) superior a 25 se considera sobrepeso; superior a $30 \mathrm{~kg} / \mathrm{m}^{2}$ obeso; mientras que la obesidad extrema se define como un IMC superior a $40 \mathrm{~kg} / \mathrm{m}^{2}$.

La obesidad sigue la primera ley de la termodinámica en el sentido de que, si la energía consumida como calorías en los alimentos no se gasta durante la actividad física, se almacena en el cuerpo como grasa. Visto así, el origen de la obesidad puede parecer bastante fácil de explicar: si consumimos más calorías de las que necesitamos, acumulamos kilos. De esta manera, una pérdida de peso clínicamente relevante, del 5 al $10 \%$, se asocia con mejoras en las complicaciones relacionadas con la obesidad (Novo Nordisk, 2018). En su nivel más simple, el pensamiento de política pública, podría centrarse en la necesidad de abordar la dieta y la falta de actividad física.

Desafortunadamente, el problema es mucho más complejo. Parece que nuestros cuerpos están programados para conservar esas calorías adicionales, probablemente porque durante miles de años fue un mecanismo básico de supervivencia. Durante la pérdida de peso, los cambios en las hormonas involucradas en la regulación homeostática hacen que el cuerpo conserve energía (Mads, 2018). Para las personas con obesidad, esto significa que su cuerpo resiste la pérdida de peso y superar este sofisticado mecanismo de defensa requiere un tratamiento a largo plazo Con frecuencia comer en exceso, también está relacionado con dificultades psicológicas, "se debe tratar al paciente de la cabeza al estómago, no solo al estómago» (Gentleman, 2013). Sin una comprensión clara de los problemas, la alimentación problemática no podrá detenerse.

Aunque, en el plano individual existen complejas interacciones a nivel biológico y físico que deben esclarecerse, la obesidad se encuentra también relacionada con los aspectos sociales de la dieta, así como con la dimensión cultural que une la dieta con la actividad física, interacciones que tradicionalmente se han minimizado. La obesidad, en este sentido, es manifestación de estructuras sociales inapropiadas que enmarcan lo que las personas comen y lo que hacen.

Para la Obesity Action Coalition (OAC, 2020), la obesidad es una enfermedad compleja, no se trata solo de comida y requiere un enfoque integral para su atención. La atención no debe considerarse simplemente como el objetivo de reducir el peso corporal, sino que, además, debe centrarse en mejorar la salud y la calidad de vida en general. La obesidad va más allá de ser una condición de elección personal. Las personas afectadas con frecuencia luchan no solo con las consecuencias físicas y de salud de su enfermedad, sino también con las consecuencias profesionales y sociales. La discriminación contra las personas afectadas por la obesidad ocurre en escuelas, lugares de trabajo, consultorios médicos y más.

La obesidad es simultáneamente causa y consecuencia. Se encuentra asociada a un espectro de más de 200 complicaciones o problemas de salud, entre ellas, algunas enfermedades crónicas, como diabetes, enfermedades cardiovasculares y esteatohepatitis no alcohólica la cual, provoca lesiones hepáticas (OAC, 2020). El riesgo de estas enfermedades no transmisibles aumenta incluso cuando una persona tiene solo un ligero sobrepeso y se agrava a medida que aumenta el índice de masa corporal (WHO, 2020). 
No obstante, su estrecha interconexión, los factores de riesgo extrínsecos intrínsecos y ambientales individuales de la obesidad tienden a considerarse por separado limitando el enfoque y las opciones de tratamiento (Novo Nordisk 2018; Scarborough y Allender, 2008). Demasiados análisis de la obesidad, están encerrados en «casillas» disciplinarias, dado el espectro de factores involucrados, es necesario un análisis interdisciplinario más amplio y una respuesta sostenida de toda la sociedad. Pero también, la naturaleza multicausal o multifactorial de la obesidad, pone en entredicho las estructuras y compartimentos convencionales existentes en los gobiernos al ser poco probable que funcionen las «soluciones rápidas» o las dirigidas a un solo factor.

De acuerdo a la Organización Panamericana de la Salud (PAHO, 2020), los problemas vinculados al bienestar y la calidad de vida como la salud y la obesidad, precisan de la intervención coordinada de instituciones pertenecientes a diferentes sectores o áreas de política. Si bien, el sector salud tiene la principal responsabilidad de mejorar y promover las condiciones sanitarias de la población, muchos determinantes están fuera del control directo del sector. La Agenda 2030 y sus ODS establecen principios y metas para hacer frente a los desafíos en esta materia, destacando el papel del Estado como actor principal en la gobernanza de la salud y en la promoción de la asociación con socios no gubernamentales (ONU, 2020).

La Agenda 2030 aboga por iniciativas interinstitucionales que aborden los determinantes clave de la salud bajo la influencia de acciones de sistemas e instituciones que quedan fuera del ámbito tradicional del sector salud (FLACSO, 2015). Es preciso desarrollar una visión amplia de los temas o problemas comunes como la obesidad, que se refleje en los planes y presupuestos de cada uno de los actores involucrados.

\subsection{Dimensión espacial}

La obesidad como parte de los grandes problemas sociales de nuestro tiempo, son cuestiones que atraviesan los límites espaciales o territoriales en diferentes escalas: local, regional, nacional y global; se trata de fenómenos que desarrollan su propia geografía. La OMS (2017) ha calificado la situación de la obesidad como una epidemia que saltó de los países ricos al mundo en desarrollo.

Nos encontramos ante una nueva realidad en la cual, la globalización ha jugado un papel importante en la configuración de las opciones alimentarias (Gornitzka, 2020). Ya no podemos caracterizar a los países como de bajos ingresos y desnutridos o, a los de altos ingresos sólo preocupados por la obesidad. Por ejemplo, entre los países de la OCDE, México tiene la segunda tasa más alta de obesidad, después de Estados Unidos, seguido de cerca por Nueva Zelanda y Hungría. La obesidad ha venido aumentando dramáticamente en los países pobres y de ingresos medios: China, India y Brasil están lidiando con la epidemia (OECD, 2017). Por la malnutrición, actualmente hay más personas obesas que, con bajo peso en todas las regiones, excepto en África subsahariana y Asia (Branca, 2019).

En esta dimensión espacial, llaman la atención los planos norte-sur, occidente-oriente. La occidentalización se ha sugerido como un impulsor adicional del aumento de la obesidad en numerosos países (Scarborough y Allender, 2008). La industria de la comida rápida o fast food y las tasas de obesidad han aumentado rápidamente. La obtención de mayores ingresos, la urbanización, un estilo de vida más ocupado, el crecimiento del servicio de comida rápida, la garantía de seguridad alimentaria, así como las nuevas marcas y alimentos son factores estrechamente relacionados.

Diversos estudios han documentado el crecimiento de la industria fast food con el riesgo de obesidad. En 2016, se encontró que la industria de comida rápida en China, abarcaba más de dos millones de instalaciones; que sus ingresos totales en dólares, aumentaron de 10.464 en 1999 a 94.218 en 2013 , y en un $13 \%$ anual de 2008 a 2016 (Wang et al., 2016). La acelerada expansión de los restaurantes de estilo occidental ha estimulado el crecimiento de la industria de comida rápida local.

Dentro de los propios países, existen importantes disparidades geográficas en la prevalencia de obesidad y sus factores de riesgo. Aunque el problema de la obesidad forma parte de la agenda nacional de muchos gobiernos, el fenómeno afecta a las regiones de forma diferenciada según las disparidades sociales y económicas de la población. La geografía, clase social y la situación económica desempeñan papeles decisivos en la configuración del problema de la obesidad. Algunas de las zonas más afectadas por bajos niveles de ingreso y de educación, son también donde la epidemia de la obesidad se presenta con mayor intensidad.

En aspectos clave de la salud, a los residentes de las zonas rurales les va peor que a los residentes de las zonas más urbanizadas. El lugar se residencia se entrecruza con otros factores sociales, económicos y culturales; la raza, etnia y el porcentaje de kilocalorías de grasa, son con frecuencia, correlatos significativos de la obesidad entre habitantes rurales y urbanos (Eberhardt y Pamuk, 2004). El sobrepeso y la obesidad 
también se han relacionado con factores de riesgo ambiental característico de las áreas urbanas de residencia (Atek et al., 2013).

Para la formulación de las políticas, el análisis de las variaciones geográficas en la prevalencia de afecciones crónicas, como el sobrepeso y la obesidad, deben ser una herramienta importante que permite identificar los puntos críticos e informar la asignación de fondos para políticas y campañas de promoción de la salud, aunque hay que reconocer que rara vez se realizan (Samouda et al., 2018).

Está claro que, como la obesidad, muchos de los problemas sociales actuales además de atravesar los dominios de política y los horizontes temporales, sobrepasan las fronteras geográficas. A medida que las causas y consecuencias de tales fenómenos se extienden, se hace cada vez más difícil para los gobiernos de los distintos niveles actuar de manera unilateral.

\subsection{Dimensión temporal}

Como lo hemos planteado, los problemas sociales complejos conllevan causas, procesos, consecuencias y soluciones de largo plazo. La mayoría de ellos, son la expresión de una serie de factores económicos, sociales, políticos y culturales combinados, acumulados históricamente, no resueltos y agravados por la aparición de otros nuevos.

El término latencia es ilustrativo del papel que desempeña la variable tiempo en el desarrollo los problemas de salud. Se define como tiempo que transcurre entre la exposición a algo que puede causar enfermedades como la radiación o un virus, y los síntomas (Merriam, 2020). Denota también, el período de incubación de una enfermedad o el intervalo entre estímulo y respuesta. En el caso que nos ocupa, la latencia es el periodo que media entre el inicio de la obesidad y la aparición de la enfermedad.

Muchas veces marginada en los titulares de los medios de comunicación, la obesidad constituye una grave amenaza para la salud pública que, continúa aumentando dramáticamente (Blumenthal y Seervai, 2018). Las epidemias que evolucionan más lentamente no necesariamente dan más tiempo para reaccionar. De hecho, al crecer lentamente pueden ser mucho más difíciles de abordar y revertir; además de que pueden tener un impacto mucho mayor y más duradero. Lee (2016), apunta que cada vez hay más evidencia de que la obesidad es una catástrofe global en cámara lenta o en slow motion. Agrega, que quizás si la epidemia mundial de obesidad avanzara más rápido, obtendría una respuesta de emergencia similar a la del ébola, el zika y otras epidemias de enfermedades infecciosas que se han impactado al mundo en los últimos años.

A nivel personal, se trata de un problema complejo que se extiende a lo largo de la vida lo cual, significa también que hay oportunidades para abordar el problema a lo largo de la vida. Por ejemplo, el primer día una madre que amamanta tiene menos probabilidades de tener hijos obesos y es menos probable tener sobrepeso ella misma (PAHO, 2020).

Como problema de salud pública, la latencia tiene que ver con su desarrollo como fenómeno social. De este modo, más que ser un shock repentino para la sociedad, la obesidad es un problema que ha tardado décadas en desarrollarse. El ritmo y escala en el aumento de la obesidad debe verse como resultado de un largo proceso de cambio social (Lang y Rayner, 2007).

La obesidad es muestra clara de problemas con un patrón de deterioro lento el cual, se extiende más allá del plazo en que los gobiernos elaboran presupuestos o planifican estratégicamente (Olson, 2016). Problemas en los que a menudo, se ignoraran las pruebas o alertas tempranas sobre los peligros que representan (EEA, 2013).

Por ejemplo, al ser producto de los estragos prolongados de más de cuatro décadas de mala alimentación, la epidemia de obesidad en México y Estados Unidos, se conecta con la pandemia de COVID-19, lo que hace a estos dos países especialmente vulnerables al coronavirus (González, 2020). Y es que, junto a Estados Unidos, México tiene el dudoso honor de estar en lo más alto del ranking mundial de países con la mayor tasa de sobrepeso entre la población de adultos (OECD, 2017).

Como fenómeno multifactorial (dimensión causal) y de larga data (dimensión temporal), la búsqueda de soluciones debe ser la investigación no solo de cuáles han sido los impulsores de la obesidad en el tiempo, sino también de cómo interactúan. Dada su evolución temporal, es probable que lleve muchos años controlar problema de la obesidad. De hecho, al día de hoy, ningún país ha logrado revertir las tendencias de obesidad, o al menos, no de manera significativa (Lang y Rayner, 2007).

Abundando un poco más en la dimensión temporal de los problemas de salud pública, y con ello, en el concepto de latencia, el caso del atentado al World Trade Center es ilustrativo del tiempo que transcurre entre la exposición a la radiación y los síntomas. Se ha documentado que las víctimas del 11 de septiembre, 
han llegado en tres oleadas (Lester, 2019). La primera, representada por las muertes y heridas inmediatas causadas por el colapso de las torres gemelas. La segunda oleada, por los trastornos aerodigestivos relacionados con la inhalación de partículas liberadas por la explosión, incluido el trastorno de reflujo gastroesofágico, y rinosinusitis crónica, los cuales fueron diagnosticados años más tarde entre los sobrevivientes. La tercera oleada, podría estar compuesta por personas expuestas a polvos cancerígenos de la Zona Cero desarrollaron la enfermedad en periodos de más de veinte años. Para los médicos del Programa de Salud del World Trade Center en las próximas décadas, el número de personas afectadas puede aumentar.

La dimensión temporal, permite observar también que los problemas complejos de salud, como la obesidad, son dinámicos. Un mismo fenómeno en el tiempo, puede variar de un estado a otro y, de un nivel de complejidad a otro mayor (Ramis, 2004). La dimensión temporal de los problemas de salud, tiene importantes implicaciones en términos de política pública, debido a que uno de los referentes que estructuran a los aparatos del gobierno es la duración acotada o limitada de los ciclos de gobierno. Existe un desacompasamiento entre tiempos institucionales generalmente cortos, y la temporalidad de problemas sociales que muchas veces, socava la capacidad de los gobiernos para satisfacer demandas apremiantes. Sin embargo, el calendario político exige resultados rápidos.

\section{CONCLUSIONES Y RECOMENDACIONES}

De acuerdo con los objetivos del artículo, podemos concluir que el análisis del caso de la epidemia de obesidad permitió operacionalizar su complejidad como problema de política pública, a partir de las dimensiones causal, espacial y temporal, versus los referentes de actuación sectorial, territorial y por duración de ciclo de gobierno que tradicionalmente enmarcan la forma en que los gobiernos abordan los problemas públicos y conciben sus soluciones. Del análisis se desprende que los marcos de actuación predominantes no están sincronizados con grandes los problemas del siglo XXI, los resultados limitados de muchas políticas hasta ahora aplicadas están indicando insuficiencias severas en los referentes en los que se apoyan.

A continuación, se sugieren algunas orientaciones de carácter intersectorial, intergubernamental y de largo plazo para formular políticas públicas que amplíen las posibilidades al encarar los problemas públicos complejos, como la epidemia de obesidad que aquí se ha analizado. Si aceptamos que el camino para la acción ha de estar determinado por la propia naturaleza de los problemas sociales, es posible enunciar una serie de características básicas para la formulación de las políticas: i) intersectoriales, dado su carácter multicausal, ii) intergubernamentales, porque no distinguen fronteras geográficas y, iii) de largo aliento por su temporalidad.

Intersectoriales. Este primer atributo se vincula con un cambio de orientación del quehacer gubernamental, reflejo de asuntos cuya atención no corresponde exclusivamente a una institución, sector o nivel de gobierno, sino a una combinación de ellos. Cuando un asunto se concibe como transversal, se trata de un tema que compromete la agenda de múltiples áreas de política y dominios de las diferentes esferas de gobierno; son temas en los que gran cantidad de instituciones se ven implicadas. Se requiere que las políticas actúen alineadas a la lógica de los actuales problemas sociales; ante la transversalidad se precisa una respuesta multisectorial. En otras palabras, las distintas manifestaciones de los problemas sociales exigen que las políticas y programas públicos se complementen entre sí. Frente a esta transversalidad, las desconexiones entre los gobiernos y sus organizaciones tienen graves consecuencias; una actuación aislada y focalizada sobre un determinado factor, puede reducir significativamente las posibilidades de incidir en ellas, a la vez que aumenta el riesgo de un uso ineficiente de los recursos públicos.

Intergubernamentales. La naturaleza compleja de los grandes temas sociales reside en que no son cuestiones que incumban exclusivamente a un sector o nivel de gobierno. Ello plantea respuestas en dos niveles: intra e intergubernamental. Como se mencionó en el punto anterior, en el primer caso, se concreta a través de políticas multisectoriales basadas en la conjunción de esfuerzos, conocimientos y recursos de diversas dependencias y entidades de un gobierno. En el segundo, conllevan, además la coordinación entre instituciones de gobiernos distintos, de igual o diferente nivel. La «intersectorialidad» e «intergubermentalidad», son modalidades de respuesta cada vez más necesarias de la administración pública en un entorno complejo, pero también una manifestación de su propia complejidad interna. Las relaciones intergubernamentales han venido adquiriendo cada vez mayor importancia. De manera inexorable, iniciativas públicas de escala nacional deben ser implementadas a través del involucramiento de numerosas organizaciones de 
distintos niveles de gobierno con lo que una importante proporción de programas son en realidad resultado de este tipo de esfuerzos.

De largo aliento. Los horizontes de tiempo que requieren las políticas orientadas a los grandes problemas sociales casi nunca van a coincidir con los ciclos o periodos gubernamentales, ya que se trata de cuestiones que tienen cronologías distintas. Esta característica, se refiere no solo a la permanencia en el tiempo, sino a una visión de futuro que tenga en cuenta dónde se quiere llegar: se precisa pensar en lo que se tiene, en lo deseado, en lo posible y en lo probable. Supone pasar de una visión ideológica, partidista y de corto plazo, a una visión compartida, con sentido de Estado y de futuro. El largo plazo tiene que ver no sólo con la magnitud de la situación o problema sobre el que se busca incidir, sino también porque involucra ciclos de larga maduración. No se trata, por tanto, de políticas coyunturales o acotadas a la duración de los periodos gubernamentales, sino de políticas de "gran aliento». Optar por esta clase de políticas, es elegir políticas que rendirán beneficios de largo plazo y que, en la mayoría de los casos, deben desarrollarse más allá de un ciclo gubernamental. Aunque suponen horizontes de tiempo amplios, las políticas necesitan de combinar estrategias de mediano y largo plazo con las de corto plazo.

Las tres características mencionadas deben integrarse en una estrategia integral coherente para mejorar la salud de la población. En primer término, porque la acción intersectorial es fundamental en el logro de una mayor efectividad en la salud y atención de la obesidad, en especial cuando el progreso depende de las decisiones y acciones vinculadas a otros sectores de política pública. En segundo lugar, porque es preciso aunar esfuerzos de los gobiernos implicados jurisdiccionalmente a nivel local, subnacional y nacional. y, en tercer lugar, porque la obesidad que, ha tardado décadas en desarrollarse, llevará también muchos años controlarla. El aumento en su ritmo y escala deben abordarse como resultado de un proceso de cambio social, económico y tecnológico.

Se trata de una enfermedad multifactorial, ampliamente extendida y crónica que representa una de las principales causas de muerte evitables en el mundo, y se encuentra asociada con una gran cantidad de afecciones. Más que una condición de elección personal, las enfermedades relacionadas con la dieta son causadas por un sistema alimentario disfuncional. De ahí, que la atención no deba centrarse únicamente en el objetivo de reducir el peso corporal, sino el mejoramiento de la salud y la calidad de vida de la sociedad en general.

La obesidad se encuentra concatenada con otros problemas sociales y de salud, por lo que sólo las políticas públicas integrales, que aborden simultáneamente todos los problemas sociales básicos, tienen posibilidades funcionar. En el campo de la salud, la perspectiva sistémica sugiere evaluar el problema en cuestión, colocarlo en un contexto lo suficientemente amplio y pensar que se trata de un sistema o parte de uno.

En suma, si realmente deseamos entender y abordar los grandes desafíos que enfrentamos como sociedad, como los que tienen que ver con la salud y la alimentación, necesitamos replantear de fondo los referentes que han guiado el estudio, la organización y quehacer de los gobiernos. Solo cuando este tipo de cuestiones se ven en su complejidad, a través de una lente de sistemas, podremos evaluar adecuadamente el problema, las soluciones y sus riesgos.

\section{REFERENCIAS BIBLIOGRÁFICAS}

Ackoff, R. L. (1974). Redesigning the future: A systems approach to societal problems. John Wiley \& Sons Inc.

Allen, T. W. (2017). Recognizing and Responding to Today's Governance Challenges. Public Administration Review, 77(4), 483-484. https://doi.org/10.1111/puar.12804

Atek, M., Traissac, P., El Ati, J., Laid, Y., Aounallah-Skhiri, H., Eymard-Duvernay, S., Mézimèche, N., Bougatef, S., Béji, C., Boutekdjiret, L., Martin-Prével, Y., Lebcir, H., Gartner, A., Kolsteren, P., Delpeuch, F., Ben Romdhane, H. y Maire, B. (2013). Obesity and association with area of residence, gender and socio-economic factors in Algerian and Tunisian adults. PLoS One, 8(10). https://doi.org/10.1371/journal.pone.0075640.

Bacchi, C. (2009). Analysing policy: what's the problem represented to be? Frenchs Forest. N. S. W. Pearson Education.

Barkan, S. E. (2014). A Primer on Social Problems. https://2012books.lardbucket.org/books/a-primer-on-socialproblems/

Bassets, M. (2020, 8 de marzo). El virus que bloquea el mundo. El País. https://elpais.com/sociedad/2020/03/06/ actualidad/1583521165_442049.html

Beck, U. (1998). La sociedad del riesgo. Hacia una nueva modernidad. Paidós.

Bendor, J. (2015). Incrementalism: Dead yet Flourishing. Public Administration Review, 75(2), 194-205. https://doi. org/10.1111/puar. 12333 
Blondin, D. y Boin, A. (2020). Cooperation in the Face of Transboundary Crisis: A Framework for Analysis. Perspectives on Public Management and Governance, 3(3), 197-209. https://doi.org/10.1093/ppmgov/gvz031

Blumenthal, D. y Seervai, S. (2018). Rising Obesity in the United States is a Public Health Crisis. The Commonwealth Fund. https://www.commonwealthfund.org/blog/2018/rising-obesity-united-states-public-health-crisis

Boston, J. (2017). Anticipatory governance: How well is New Zealand safeguarding the future? Policy Quarterly, 12(3), 11-24. https://doi.org/10.26686/pq.v12i3.4614

Branca, F. (2019, 25 de septiembre). Malnutrition is a world health crisis. WHO. https://www.who.int/news/item/26-092019-malnutrition-is-a-world-health-crisis

Brugué, Q. (2014). Políticas Públicas: Entre la deliberación y el ejercicio de autoridad. Cuadernos de Gobierno y Administración Pública, 1(1), 37-55. https://doi.org/10.5209/rev_CGAP.2014.v1.n1.45157

Bryson, J. M., Crosby, B. C. y Stone, M. M. (2006). The Design and Implementation of Cross-Sector Collaborations: Propositions from the Literature. Public Administration Review, 66(s1), 44-55. https://doi.org/10.1111/j.15406210.2006.00665.x

Capra, F. y Luigi, P. (2014). The systems view of life: a unifying vision. Cambridge University Press.

Copenhagen Institute for Futures Studies - CIFS (2019). Your life in 2044. https://am.pictet/-/media/pam/pam-commongallery/article-content/2019/pictet-asset-management/understanding-megatrends/your-life-in-2044.pdf

Copenhagen Institute for Futures Studies - CIFS (2020). Pandemics. Existential risks and enablers of change. https:// cifs.dk/news/pandemics-existential-risks-and-enablers-of-change

Cifuentes, M. (2012). Developing a complex approach to health phenomena (step 1). En A. A. Minai, D. Braha e Y. BarYam (eds.), Unifying Themes in Complex Systems VII (pp. 27-35). Springer. https://doi.org/10.1007/978-3-64218003-3_3

Courtney, J. F. (2001). Decision making and knowledge management in inquiring organizations: Toward a new decision-making paradigm for DSS. Decision Support Systems, 31(1), 17-38. https://doi.org/10.1016/S01679236(00)00117-2

Covarrubias, O. M. (2018). Problemas complejos, transversalidad y coordinación en el federalismo. Centro Latinoamericano de Administración para el Desarrollo CLAD.

Covarrubias, O. M. (2020). VUCA World y lecciones de interdependencia COVID-19. GIGAPP Estudios Working Papers, 7(182-189), 513-532. http://www.gigapp.org/ewp/index.php/GIGAPP-EWP/article/view/225

De Domenico, M. y Sayama, D. (coords.) (2019). Complexity Explained. https://complexityexplained.github.io/

Eberhardt, M. S. y Pamuk, E. R. (2004). The importance of place of residence: examining health in rural and nonrural areas. American journal of public health, 94(10), 1682-1686. https://doi.org/10.2105/ajph.94.10.1682

European Environment Agency Report - EEA (2013). Late lessons from early warnings: science, precaution, innovation, 1/2013. https://www.eea.europa.eu/publications/late-lessons-2

Facultad Latinoamericana de Ciencias Sociales (FLACSO) (2015). Informe Técnico para el Diseño de Plan de Trabajo para reorientación de Programas de Salud Pública.

Gentleman, A. (2013, 19 de febrero). How psychology can beat obesity. The Guardian. https://www.theguardian.com/ society/2013/feb/19/patient-stomach-psychology-obesity

Gershenson, C. (2006). ¿Cómo hablar de complejidad? Instituto de Investigaciones en Matemáticas Aplicadas y en Sistemas y Centro de Ciencias de la Complejidad, UNAM.

González, M. (2020, 6 de abril). Coronavirus en México y Estados Unidos: la otra epidemia que hace a estos dos países especialmente vulnerables al COVID-19. BBC. https://www.bbc.com/mundo/noticias-america-latina-52154197

Gornitzka, P. C. (2020, 9 de enero). Obesity isn't an unstoppable trend-here's what we can do differently. World Economic Forum. https://www.weforum.org/agenda/2020/01/obesity-crisis-how-we-can-help-children-to-eat-better/

Head, B. W. (2019). Forty years of wicked problems literature: forging closer links to policy studies. Policy and Society, 38(2), 180-197. https://doi.org/10.1080/14494035.2018.1488797

Hébert-Dufresne, L., Scarpino, S. V. y Young, J.-G. (2020). Macroscopic patterns of interacting contagions are indistinguishable from social reinforcement. Nature Physics, 16, 426-431. https://doi.org/10.1038/s41567-0200791-2

Hurt, R., Kulisek, C., Buchanan, L. y McClave, S. (2010). La epidemia de obesidad: desafíos, iniciativas de salud e implicaciones para los gastroenterólogos. Gastroenterología y hepatología, 6(12), 780-792. https://www.ncbi.nlm. nih.gov/pmc/articles/PMC3033553/

IATA (2018, 24 de octubre). Forecast Predicts 8.2 billion Air Travelers in 2037. https://www.iata.org/en/pressroom/ pr/2018-10-24-02/

International Diabetes Federation - IDF (2019). Diabetes Atlas. https://diabetesatlas.org/en/

Innerarity, D. (2009). El futuro y sus enemigos. Paidós.

Innerarity, D. (2010, 9 de junio). Una política de la humanidad. El País. https://elpais.com/diario/2010/06/09/ opinion/1276034404_850215.html

Innerarity, D. y Solana, J. (2011). La humanidad amenazada. Paidós.

Johnson, J. (2006). Can complexity help us better understand risk? Risk Management, 8, 227-267. https://doi. org/10.1057/palgrave.rm.8250023

Kahneman, D. (2020). Pensar rápido, pensar despacio. Penguin Random House. 
Lang, T. y Rayner, G. (2007). Overcoming policy cacophony on obesity: an ecological public health framework for policy makers. Obesity Reviews, 8(s1), 165-181. https://doi.org/10.1111/j.1467-789X.2007.00338.x

Lee, B. Y. (2016). More Evidence that Obesity is a Global Catastrophe in Slow Motion. Forbes. https://www.forbes.com/ sites/brucelee/2016/04/07/more-evidence-that-obesity-is-a-global-catastrophe-in-slow-motion/?sh=1d6bd64b44fe

Lenoir, R. (1986). Groupes de pression et groupes consensuels. Conuibution i une analyse de la forrnation du droit. Actes de la Recberche. Sciences Sociales, 64, 30-39. https://doi.org/10.3406/ARSS.1986.2334

Lester, C. (2019, 11 de septiembre). The Continuing Legacy of 9/11. The New Yorker. https://www.newyorker.com/news/ news-desk/the-continuing-legacy-of-911

Luke, J. S. (1998). Catalytic Leadership: Strategies for an Interconnected World. Jossey-Bass.

Mads, T.-Ch. (2018). Obesity-the brain is the battleground. Novo Nordisk. https://www.novonordisk.com/disease-areas/ obesity/obesity-the-brain-is-the-battleground.html

Mballa, L. V. (2015). Public Policies as a Government challenge to fight against Poverty in San Luis Potosí. GEInternational Journal of Management Research, 3(12), 99-112.

Menegoz, L. (2003). La transversalité. Une utopie organisationnelle contemporaine. Unversite Pierre Mendes.

Mills, W. (1959). The Sociological Imagination. Oxford University Press.

Mitchell, M. (2009). Complexity: A guided tour. Oxford University Press.

Morcol, G. (2012). A complexity theory for public policy. Routledge.

Morin, E. (2006). Restricted complexity, general complexity. http://www.cogprints.org/5217/

Novo Nordisk (2018). Obesity. https://www.novonordisk.com/disease-areas/obesity.html

OAC (2020). What is Obesity \& Severe Obesity? https://www.obesityaction.org/get-educated/understanding-yourweight-and-health/what-is-obesity/

OECD (2014). Mainstreaming cross-cutting issues. 7 Lessons from DAC Peer Reviews. https://www.oecd.org/dac/ mainstreaming-cross-cutting-issues-9789264205147-en.htm

OECD (2017). Obesity Update 2017. https://www.oecd.org/health/obesity-update.htm

OECD (2019). The Heavy Burden of Obesity. The Economics of Prevention. http://www.oecd.org/health/the-heavyburden-of-obesity-67450d67-en.htm

Olson, R. (2016, 25 de abril). Missing the Slow Train: How Gradual Change Undermines Public Policy \& Collective Action. Wilson center forgotten problems project. Woodrow Wilson International Center for Scholars. https://www. wilsoncenter.org/event/missing-the-slow-train-how-gradual-change-undermines-public-policy-collective-action

OMS, OPS (2017). Documento conceptual: intersectorialidad. https://www.paho.org/hq/dmdocuments/2017/promocionsalud-intersectorialidad-concurso-2017.pdf

ONU (2020). La Agenda para el Desarrollo Sostenible (ODS). https://www.un.org/sustainabledevelopment/es/ development-agenda/

Pan American Health Organization - PAHO (2020). Obesity: Complex Problem Needing an All-of-Society Approach. https://www.paho.org/hq/index.php?option=com_content\&view=article\&id=6123:2011-obesity-complex-problemneeding-all-society-approach\&ltemid=135\&lang=en

Peters, G. B. (2005). The Problem of Policy Problems. Journal of Comparative Policy Analysis: Research and Practice, 7(4), 349-370. https://doi.org/10.1080/13876980500319204

Prats, J. (2005). Política y Gestión Pública. El impacto de la globalización. Gobernanza. Revista Internacional para el Desarrollo Humano, 35.

Ramis, R. (2004). La causalidad compleja: un nuevo paradigma causal en Epidemiología. Revista Cubana de Salud Pública, 30(3).

Rein, M. y Schön, D. (1996). Frame-critical policy analysis and frame-reflective policy practice. Knowledge and Policy, 9, 85-104. https://doi.org/10.1007/BF02832235

Rescher, N. (1998). Complexity: A philosofical overview. Transaction Publishers.

Roth, A. (2002). Identificación, construcción de problemas y agenda política en Políticas Públicas: Formulación, Implementación y Evaluación. Ediciones Aurora.

Rubington, E. y Weinberg, M. S. (2010). The study of social problems: Seven perspectives. Oxford University Press.

Samouda, H., Ruiz-Castell, M., Bocquet, V., Kuemmerle, A., Chioti, A., Dadoun, F., Kandala, N.-B. y Stranges, S. (2018). Geographical variation of overweight, obesity and related risk factors: Findings from the European Health Examination Survey in Luxembourg, 2013-2015. PLOS ONE, 13(6). https://doi.org/10.1371/journal.pone.0197021

Sassen, S. (2003). Contrageografías de la globalización género y ciudadanía en los circuitos transfronterizos. Traficantes de sueños.

Scarborough, P. y Allender, S. (2008). The North-South gap in overweight and obesity in England. British Journal of Nutrition, 100(3), 677-684. https://doi.org/10.1017/S0007114508911582

Senge, P. (2006). The Fifth Discipline: The Art and Practice of the Learning Organization. Doubleday.

Sterman, J. (2006). Learning from Evidence in a Complex World. American Journal of Public Health, 96(3). https://ajph. aphapublications.org/doi/10.2105/AJPH.2005.066043

Tarlov, A. R. (1999). Public Policy Frameworks for Improving Population Health. Annals of the New York Academy of Sciences, 896(1), 281-293. https://doi.org/10.1111/j.1749-6632.1999.tb08123.x

Thaler, R. y Sunstein, C. (2008). Nudge: improving decisions about health, wealth and happiness. Yale University Press. 
The Economist (2016). The Global Crisis of Obesity. https://events.economist.com/events-conferences/emea/globalcrisis-of-obesity/

Thissen, W. A. H. (2013). Diagnosing Policy Problem Situations. En W. Thissen y W. Walker (eds.), Public Policy Analysis [International Series in Operations Research \& Management Science, vol. 179]. https://doi. org/10.1007/978-1-4614-4602-6_4

UGM Consulting (2020, 25 de noviembre). COVID-19: How The Virus IIluminates Our Vuca World. https:// ugmconsulting.com/covid-19-how-the-virus-illuminates-our-vuca-world/

University of Vermont (2020). Complexity scientists present «meme» model for multiple diseases. ScienceDaily. https:// www.sciencedaily.com/releases/2020/02/200224111409.htm

Walker, W. E., Marchau, V. A. W. J. y Kwakkel, J. H. (2013). Uncertainty in the Framework of Policy Analysis. En W. Thissen y W. Walker (eds.), Public Policy Analysis [International Series in Operations Research \& Management Science, vol. 179]. https://doi.org/10.1007/978-1-4614-4602-6_9

Wang, Y., Wang, L., Xue, H. y Qu, W. (2016). A Review of the Growth of the Fast Food Industry in China and Its Potential Impact on Obesity. 2016. International Journal of Environmental Research and Public Health, 13(11). https://doi.org/10.3390/ijerph13111112

World Health Organization - WHO (1946). Official Records of the World Health Organization, 2. https://apps.who.int/iris/ bitstream/handle/10665/85573/Official_record2 eng.pdf

World Health Organization - WHO (1986, 21 de septiembre). The Ottawa Charter for Health Promotion. https://www. who.int/teams/health-promotion/enhanced-wellbeing/first-global-conference

World Health Organization - WHO (1998). Health Promotion Glossary. https://www.who.int/publications/i/item/WHOHPR-HEP-98.1

World Health Organization - WHO (2020). Obesity. World Health Organization. https://www.who.int/health-topics/ obesity\#tab=tab_1

World Economic Forum (2015). Global Risks 2015. https://www.weforum.org/reports/global-risks-2015 